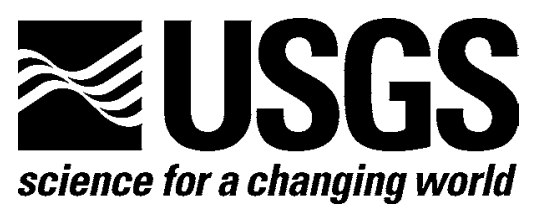

\title{
Magnetic properties of Quaternary deposits, Kenai Peninsula, Alaska - Implications for aeromagnetic anomalies of upper Cook Inlet
}

By R.W. Saltus ${ }^{1}$ and P.J. Haeussler ${ }^{2}$

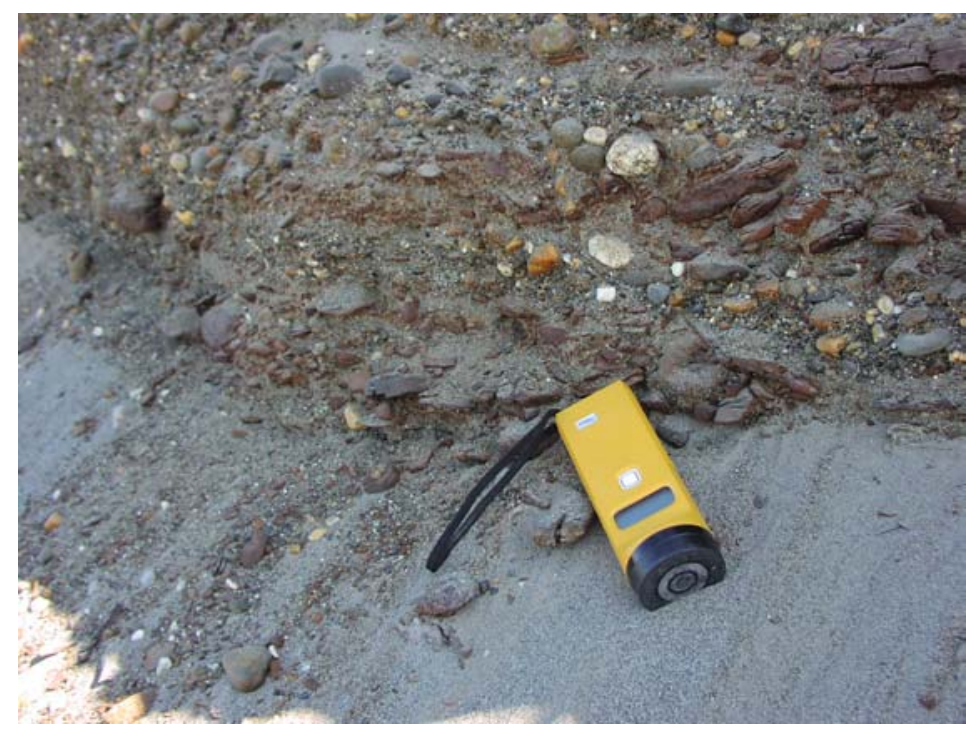

Any use of trade, firm, or product names is for descriptive purposes only and does not imply endorsement by the U.S. Government

Open-File Report 2004-1202

U.S. Department of the Interior U.S. Geological Survey

${ }^{1}$ U.S. Geological Survey, Denver, Colorado

${ }^{2}$ U.S. Geological Survey, Anchorage, Alaska 


\section{Abstract}

We measured magnetic susceptibilities of exposed Quaternary deposits on several beach cliffs and river banks on the Kenai Peninsula near Soldotna, Alaska. Data, descriptions, and photos from nine sites are included in this report. The mean susceptibility for Quaternary materials in this region is approximately $2.5 \times 10^{-3} \mathrm{SI}$ units. This is sufficiently magnetic to produce subtle aeromagnetic anomalies such as those observed to correlate with topographic features in the region of the measurements. The highest susceptibilities measured (greater than $20 \times 10^{-3} \mathrm{SI}$ units) may help, at least in part, to explain moderate amplitude aeromagnetic anomalies observed elsewhere in Cook Inlet, particularly those relating to structures showing Quaternary movement. Comparison of measured beach cliff susceptibility and susceptibility predicted from idealized formulas and twodimensional cliff models suggests that measured susceptibilies underestimate true bulk susceptibility by 20 percent to 50 percent in this region. 


\section{Contents}

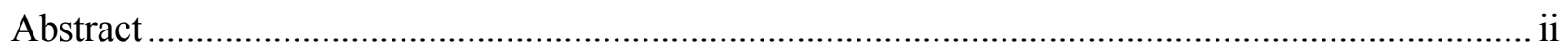

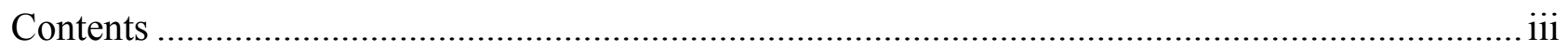



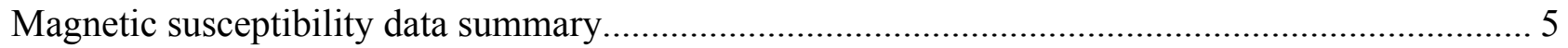

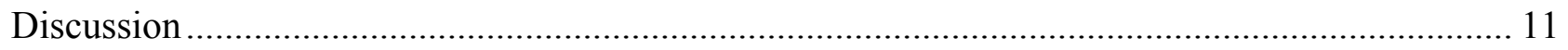

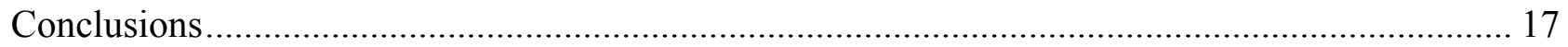

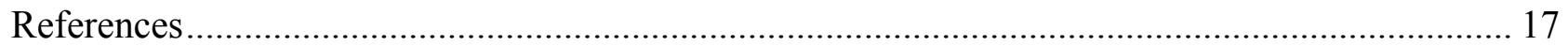

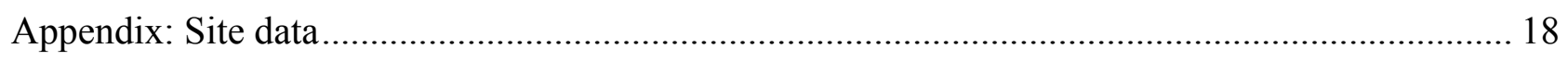

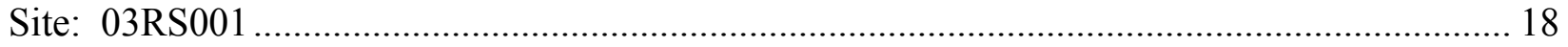

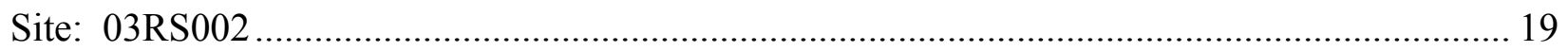



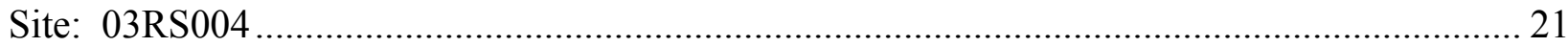

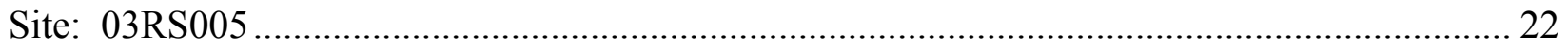

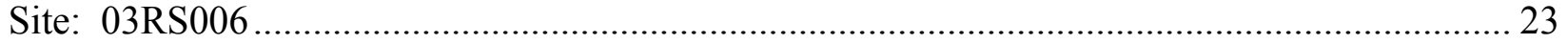

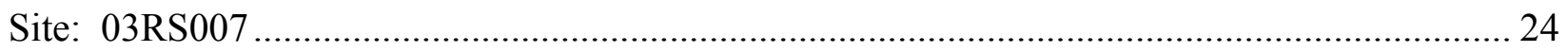

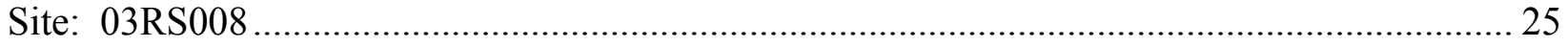

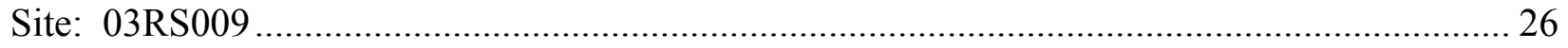




\section{Magnetic properties of Quaternary deposits, Kenai Peninsula, Alaska - Implications for aeromagnetic anomalies of upper Cook Inlet}

By R.W. Saltus ${ }^{1}$ and P.J. Haeussler ${ }^{2}$

\section{Introduction}

Detailed aeromagnetic surveys of the upper Cook Inlet (Saltus and others, 2001) show extensive short-wavelength features caused by variations in magnetic properties of surface or nearsurface Earth materials. A previous report (Altstatt and others, 2002) presented measurements of magnetic susceptibility for many of the rock units exposed in the upper Cook Inlet. However, Quaternary materials were not measured for that report. It is important to characterize the magnetic properties of the Quaternary section because it may contribute significantly to the shallow-source (high-frequency) aeromagnetic anomalies in the region. In this report we provide and discuss 471 spot measurements of magnetic susceptibility made on the Quaternary section exposed in the beach cliffs near Nikishka and a river bank and gravel bar in the Kenai River near Soldotna, Alaska (figures 1-3). The procedures and equipment used are the same as those discussed in a previous report (Altstatt and others, 2002). A hand-held susceptibility meter (Kappameter KT-6, produced by Geofyzika, a.s.) was used to make the measurements. In general, the Quaternary cliff deposits are poorly consolidated and it was possible to push the reading face of the susceptibility meter firmly against the sandy material. This reduces the chances that surface roughness produces low apparent susceptibility values. In addition to reporting the field measurements, we discuss their implications for the interpretation of shallow-source aeromagnetic anomalies in the region. 


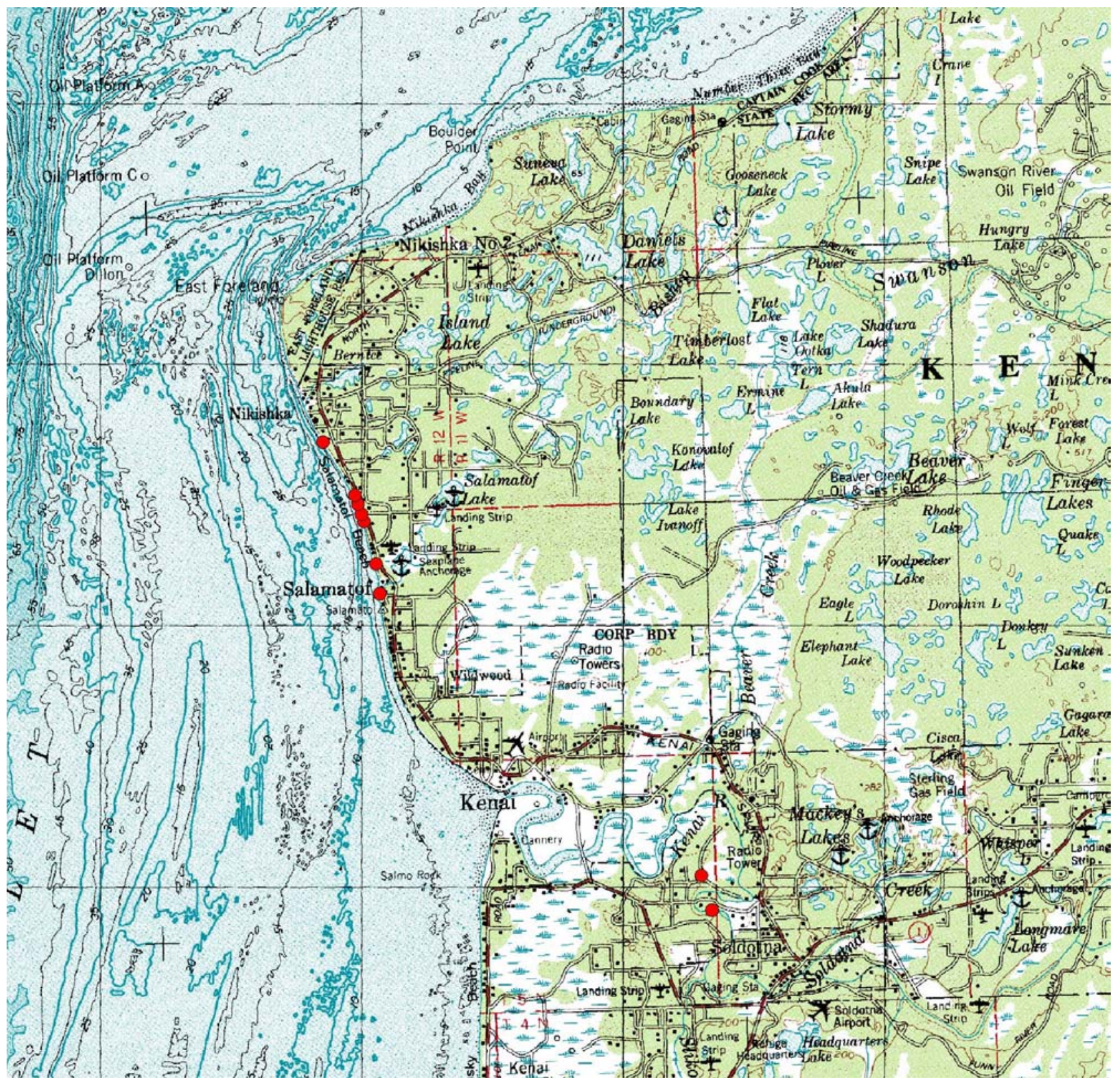

Figure 1. Field sites near Nikishka and Soldotna, Alaska. Red dots indicate sample

locations. Base map from USGS 1:250,000 Kenai Quadrangle. 


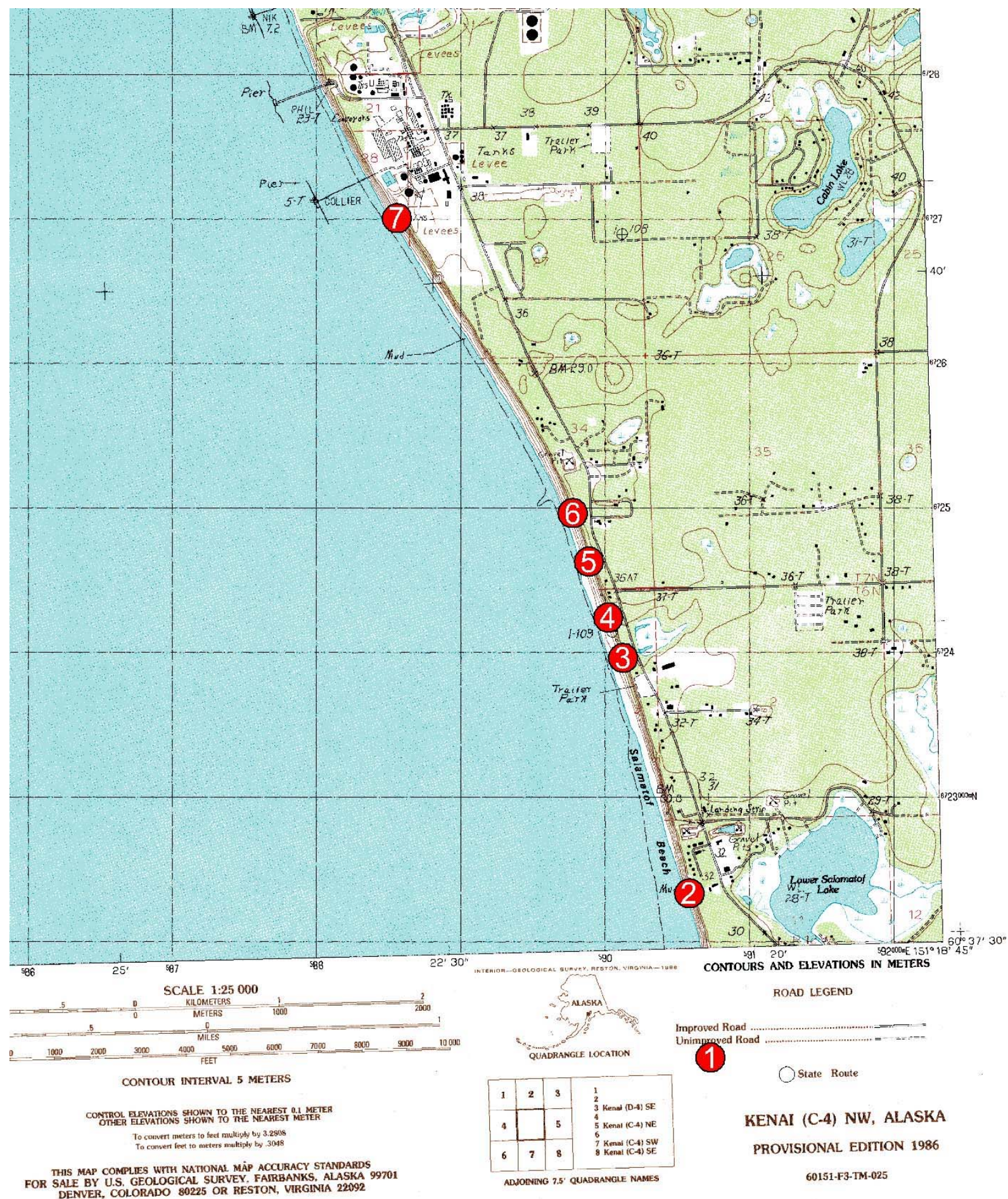

Figure 2. Red dots indicate field sites 1-7 near Nikishka, Alaska. Base map is from Kenai (C-4) NW at 1:25,000. Note that site 1 is located south of the map area. 


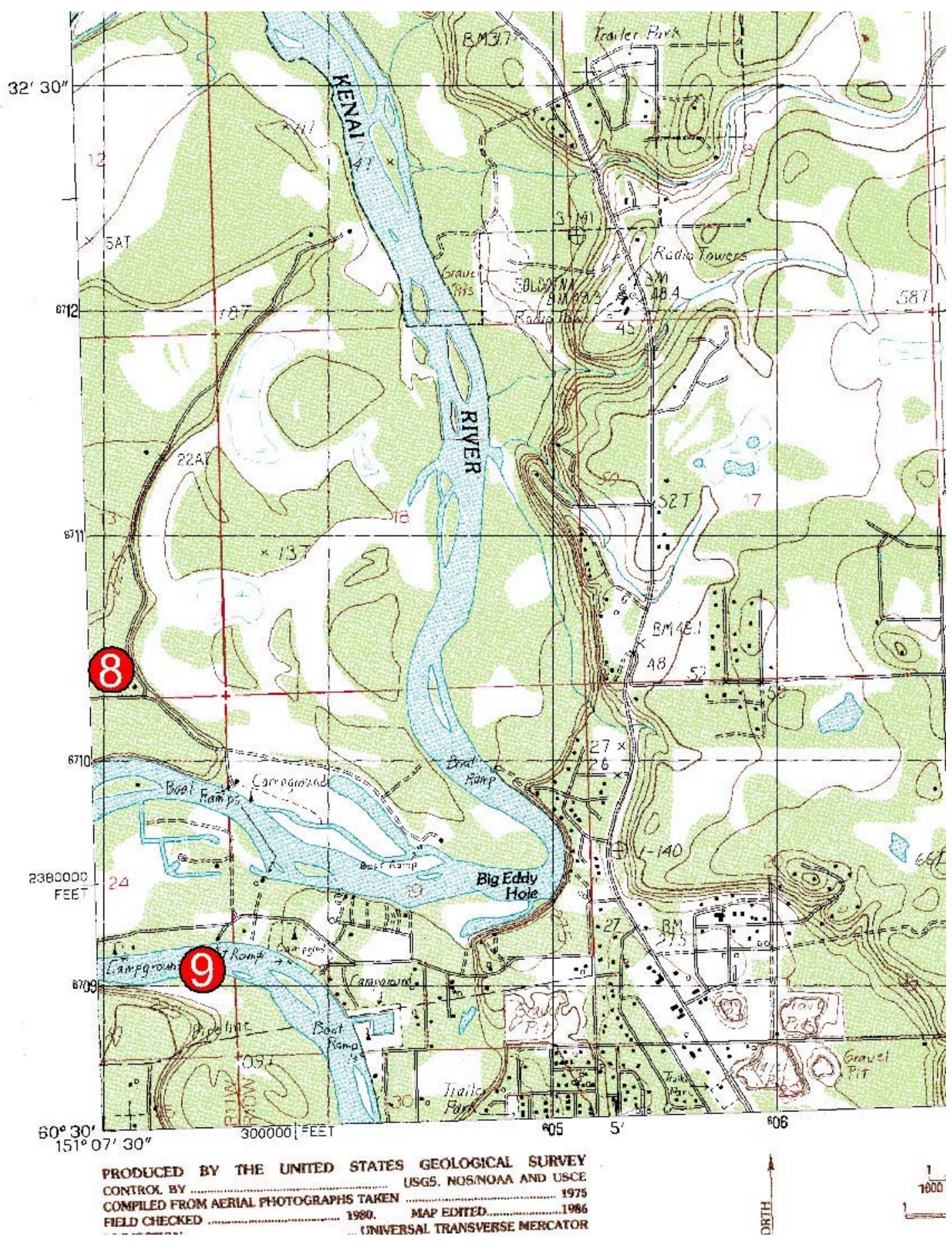

Figure 3. Red dots indicate field sites 8 and 9 near Soldotna, Alaska. Base map is from USGS 1:25,000 map Kenai (C3) SW. At time of measurement, site 8 was adjacent to an active branch of the Kenai River. Site 9 is on a gravel bar adjacent to an island. 


\section{Magnetic susceptibility data summary}

Details of the magnetic susceptibility measurements conducted at nine field sites (figures 13) are given in the Appendix. Sites 1-7 are along the Salamatof Beach near Nikishka, Alaska. Sites 8 and 9 are along the Kenai River near Soldotna, Alaska. A summary plot (figure 4) depicts the data distribution. A non-parametric statistical comparison of the susceptibility measurements from these nine sites (Tukey multiple comparison based on Kruskal-Wallis H values - table 1) suggests that data from all sites except 5 and 9 are probably part of the same statistical distribution. In other words, there is no reason statistically to consider any of these sites to be unique - they all represent samples of the same materials. Based on this result, data from all sites except 5 and 9 were analyzed together to characterize the Quaternary section as given in table 2, summarized and displayed in figure 5. 


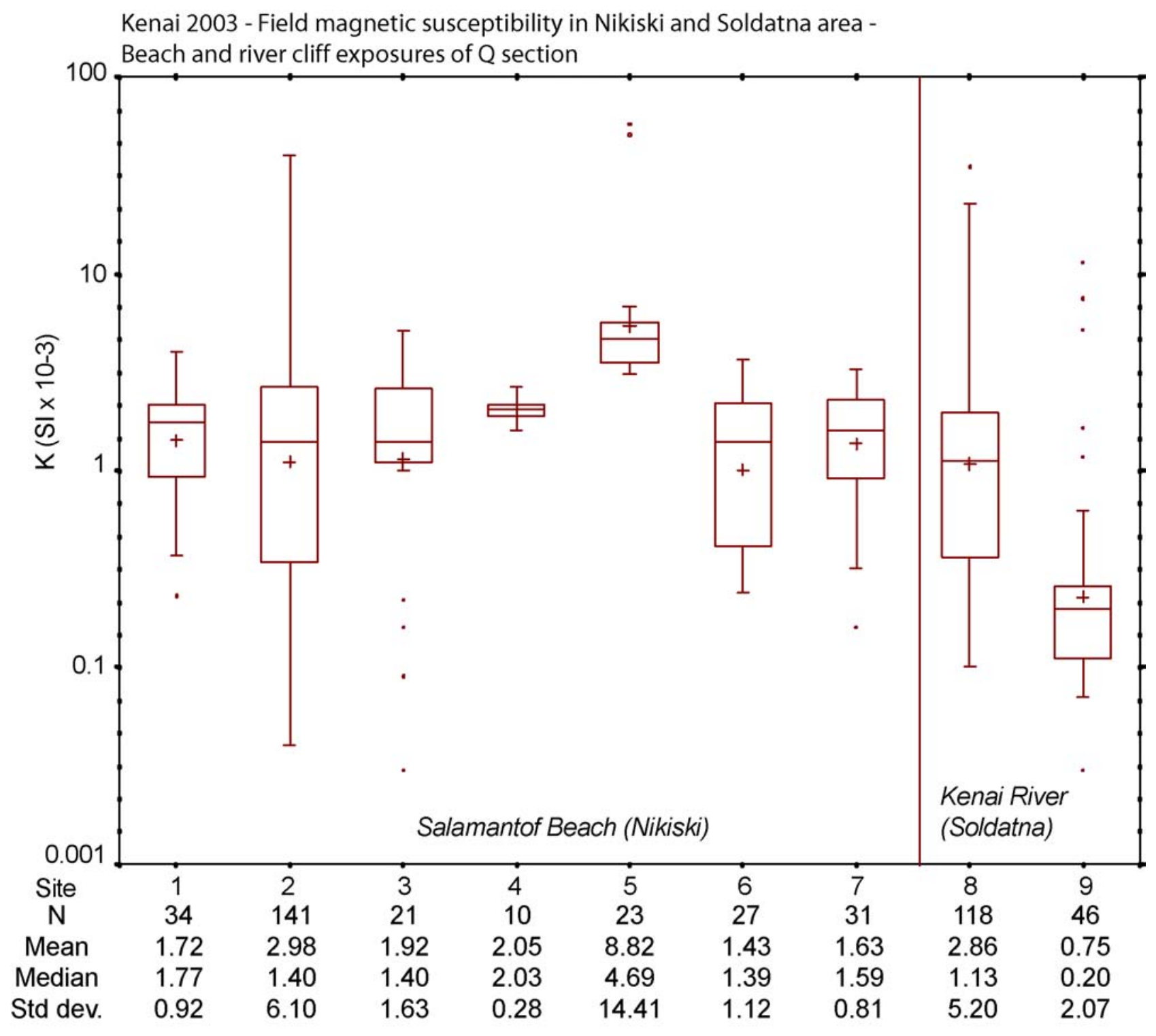

Figure 4. Box and whisker plot of measured susceptibilities from nine data sites. 
Table 1. Kruskal-Wallis test of data populations.

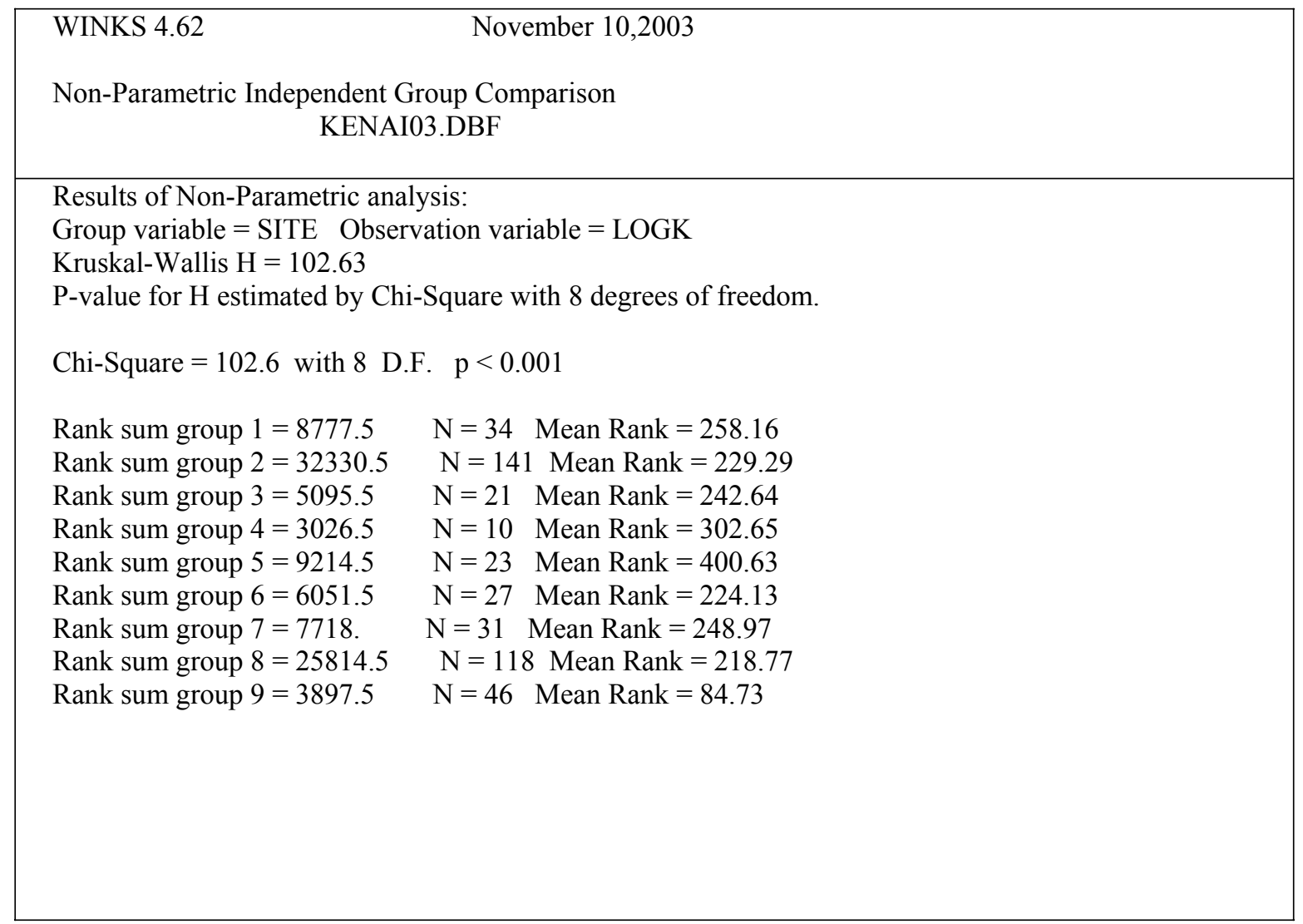




\begin{tabular}{|c|c|c|c|}
\hline \multirow{2}{*}{ Tukey Multiple Comp. } & \multicolumn{2}{|c|}{ Critical q } & \multirow{2}{*}{$(.05)$} \\
\hline & Difference & Q & \\
\hline $\begin{array}{l}\operatorname{Rank}(5)-\operatorname{Rank}(9)= \\
\quad(\mathrm{SE} \text { used }=33.2842)\end{array}$ & 315.9022 & 9.491 & $3.197 *$ \\
\hline $\begin{array}{l}\operatorname{Rank}(5)-\operatorname{Rank}(8)= \\
\quad(\mathrm{SE} \text { used }=29.7072)\end{array}$ & 181.8635 & 6.122 & $3.197 *$ \\
\hline $\begin{array}{l}\operatorname{Rank}(5)-\operatorname{Rank}(6)= \\
\quad(\mathrm{SE} \text { used }=36.9824)\end{array}$ & 176.5008 & 4.773 & $3.197 *$ \\
\hline $\begin{array}{l}\operatorname{Rank}(5)-\operatorname{Rank}(2)= \\
\quad(\mathrm{SE} \text { used }=29.3093)\end{array}$ & 171.3361 & 5.846 & $3.197 *$ \\
\hline $\begin{array}{l}\operatorname{Rank}(5)-\operatorname{Rank}(3)= \\
\quad(\mathrm{SE} \text { used }=39.3377)\end{array}$ & 157.9876 & 4.016 & $3.197 *$ \\
\hline $\begin{array}{l}\operatorname{Rank}(5)-\operatorname{Rank}(7)= \\
\quad(\mathrm{SE} \text { used }=35.8681)\end{array}$ & 151.6627 & 4.228 & $3.197 *$ \\
\hline $\begin{array}{l}\operatorname{Rank}(5)-\operatorname{Rank}(1)= \\
\quad(\mathrm{SE} \text { used }=35.1877)\end{array}$ & 142.4687 & 4.049 & $3.197 *$ \\
\hline $\begin{array}{l}\operatorname{Rank}(5)-\operatorname{Rank}(4)= \\
\quad(\mathrm{SE} \text { used }=49.3685)\end{array}$ & 97.9804 & 1.985 & 3.197 \\
\hline $\begin{array}{l}\operatorname{Rank}(4)-\operatorname{Rank}(9)= \\
\quad(\mathrm{SE} \text { used }=45.4749)\end{array}$ & 217.9217 & 4.792 & $3.197 *$ \\
\hline $\begin{array}{l}\operatorname{Rank}(4)-\operatorname{Rank}(8)= \\
\quad(\mathrm{SE} \text { used }=42.926)\end{array}$ & 83.883 & 1.954 & 3.197 \\
\hline $\begin{array}{l}\operatorname{Rank}(4)-\operatorname{Rank}(6)= \\
\quad(\mathrm{SE} \text { used }=48.2476)\end{array}$ & \multicolumn{2}{|c|}{78.5204 (Do not test) } & \\
\hline $\begin{array}{l}\operatorname{Rank}(4)-\operatorname{Rank}(2)= \\
\quad(\mathrm{SE} \text { used }=42.6516)\end{array}$ & \multicolumn{2}{|c|}{73.3557 (Do not test) } & \\
\hline $\begin{array}{l}\operatorname{Rank}(4)-\operatorname{Rank}(3)= \\
\quad(\mathrm{SE} \text { used }=50.0758)\end{array}$ & \multicolumn{2}{|c|}{60.0071 (Do not test) } & \\
\hline $\begin{array}{l}\operatorname{Rank}(4)-\operatorname{Rank}(7)= \\
\quad(\mathrm{SE} \text { used }=47.3988)\end{array}$ & \multicolumn{2}{|c|}{53.6823 (Do not test) } & \\
\hline $\begin{array}{l}\operatorname{Rank}(4)-\operatorname{Rank}(1)= \\
\quad(\mathrm{SE} \text { used }=46.886)\end{array}$ & \multicolumn{2}{|c|}{44.4882 (Do not test) } & \\
\hline $\begin{array}{l}\operatorname{Rank}(1)-\operatorname{Rank}(9)= \\
\quad(\mathrm{SE} \text { used }=29.477)\end{array}$ & 173.4335 & 5.884 & $3.197 *$ \\
\hline $\begin{array}{l}\operatorname{Rank}(1)-\operatorname{Rank}(8)= \\
\quad(\mathrm{SE} \text { used }=25.3687)\end{array}$ & \multicolumn{2}{|c|}{39.3948 (Do not test) } & \\
\hline $\begin{array}{l}\operatorname{Rank}(1)-\operatorname{Rank}(6)= \\
\quad(\mathrm{SE} \text { used }=33.597)\end{array}$ & \multicolumn{2}{|c|}{34.0322 (Do not test) } & \\
\hline $\begin{array}{l}\operatorname{Rank}(1)-\operatorname{Rank}(2)= \\
\quad(\mathrm{SE} \text { used }=24.9016)\end{array}$ & \multicolumn{2}{|c|}{28.8674 (Do not test) } & \\
\hline $\begin{array}{l}\operatorname{Rank}(1)-\operatorname{Rank}(3)= \\
\quad(\mathrm{SE} \text { used }=36.1733)\end{array}$ & \multicolumn{2}{|c|}{15.5189 (Do not test) } & \\
\hline $\begin{array}{l}\operatorname{Rank}(1)-\operatorname{Rank}(7)= \\
\quad(\mathrm{SE} \text { used }=32.3663)\end{array}$ & \multicolumn{2}{|c|}{9.194 (Do not test) } & \\
\hline $\begin{array}{l}\operatorname{Rank}(7)-\operatorname{Rank}(9)= \\
\quad(\mathrm{SE} \text { used }=30.286)\end{array}$ & 164.2395 & 5.423 & $3.197 *$ \\
\hline $\begin{array}{l}\operatorname{Rank}(7)-\operatorname{Rank}(8)= \\
\quad(\mathrm{SE} \text { used }=26.3044)\end{array}$ & \multicolumn{2}{|c|}{30.2008 (Do not test) } & \\
\hline $\begin{array}{l}\operatorname{Rank}(7)-\operatorname{Rank}(6)= \\
\quad(\mathrm{SE} \text { used }=34.309)\end{array}$ & \multicolumn{2}{|c|}{24.8381 (Do not test) } & \\
\hline $\begin{array}{l}\operatorname{Rank}(7)-\operatorname{Rank}(2)= \\
\quad(\mathrm{SE} \text { used }=25.8542)\end{array}$ & \multicolumn{2}{|c|}{19.6734 (Do not test) } & \\
\hline $\begin{array}{l}\operatorname{Rank}(7)-\operatorname{Rank}(3)= \\
\quad(\mathrm{SE} \text { used }=36.8356)\end{array}$ & \multicolumn{2}{|c|}{6.3249 (Do not test) } & \\
\hline $\begin{array}{l}\operatorname{Rank}(3)-\operatorname{Rank}(9)= \\
\quad(\mathrm{SE} \text { used }=34.3246)\end{array}$ & 157.9146 & 4.601 & $3.197 *$ \\
\hline $\begin{array}{l}\operatorname{Rank}(3)-\operatorname{Rank}(8)= \\
\quad(\mathrm{SE} \text { used }=30.8683)\end{array}$ & \multicolumn{2}{|c|}{23.8759 (Do not test) } & 8 \\
\hline $\begin{array}{l}\operatorname{Rank}(3)-\operatorname{Rank}(6)= \\
\quad(\mathrm{SE} \text { used }=37.9215)\end{array}$ & \multicolumn{2}{|c|}{18.5132 (Do not test) } & 0 \\
\hline $\operatorname{Rank}(3)-\operatorname{Rank}(2)=$ & \multicolumn{2}{|c|}{13.3485 (Do not test) } & \\
\hline
\end{tabular}


Homogeneous Populations, groups ranked Gp Gp Gp Gp Gp Gp Gp Gp Gp $\begin{array}{llllllllllll}9 & 8 & 6 & 2 & 3 & 7 & 1 & 4 & 5\end{array}$

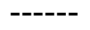

--

This is a graphical representation of the Tukey multiple comparisons test. At the 0.05 significance level, the means of any two groups underscored by the same line are not significantly different.

Table 2. Detailed statistics on susceptibility measurements from sites 1-4 and 6-8.

Descriptive Statistics

Variable Name is K

$\begin{array}{lc}\mathrm{N} \quad=382 & \text { Missing or Deleted }=0 \\ \text { Mean }=2.52872 & \text { St. Dev }(\mathrm{n}-1)=4.76264 \\ \text { Median }=1.40 & \text { St. Dev }(\mathrm{n})=4.7564 \\ \text { Minimum }=0.00 & \text { S.E.M. }=0.24368 \\ \text { Maximum }=39.70 & \text { Variance }=22.68272 \\ \text { Sum }=965.97 & \text { Coef. Var. }=1.88342\end{array}$

Percentiles:

$0.5 \%=0.02745 \quad$ Fourth $=0.41$

$2.5 \% \quad=0.12 \quad$ Median $=1.40$

$10.0 \%=0.193 \quad$ Fourth $=2.35$

$25.0 \%=0.4075$ Quartile $\quad$ Maximum $=39.70$

$50.0 \%=1.40 \quad$ Median

$75.0 \%=2.3525$ Quartile

$90.0 \%=4.31$

$97.5 \%=15.6275$

$99.5 \%=36.77201 \quad$ Test for normality results:

$100.0 \%=39.70$ Maximum $\quad \mathrm{D}=.298 \quad \mathrm{p}<=0.001$

Confidence Intervals about the mean:

$80 \%$ C.I. based on a t critical value of 1.2816 is $(2.21642,2.84101)$

$90 \%$ C.I. based on a t critical value of 1.6449 is $(2.12789,2.92954)$

$95 \%$ C.I. based on a t critical value of 1.96 is $(2.05111,3.00633)$

$98 \%$ C.I. based on a t critical value of 2.3263 is $(1.96185,3.09558)$

$99 \%$ C.I. based on a t critical value of 2.5758 is $(1.90105,3.15638)$

The normality test suggests that the data are not normally distributed. 


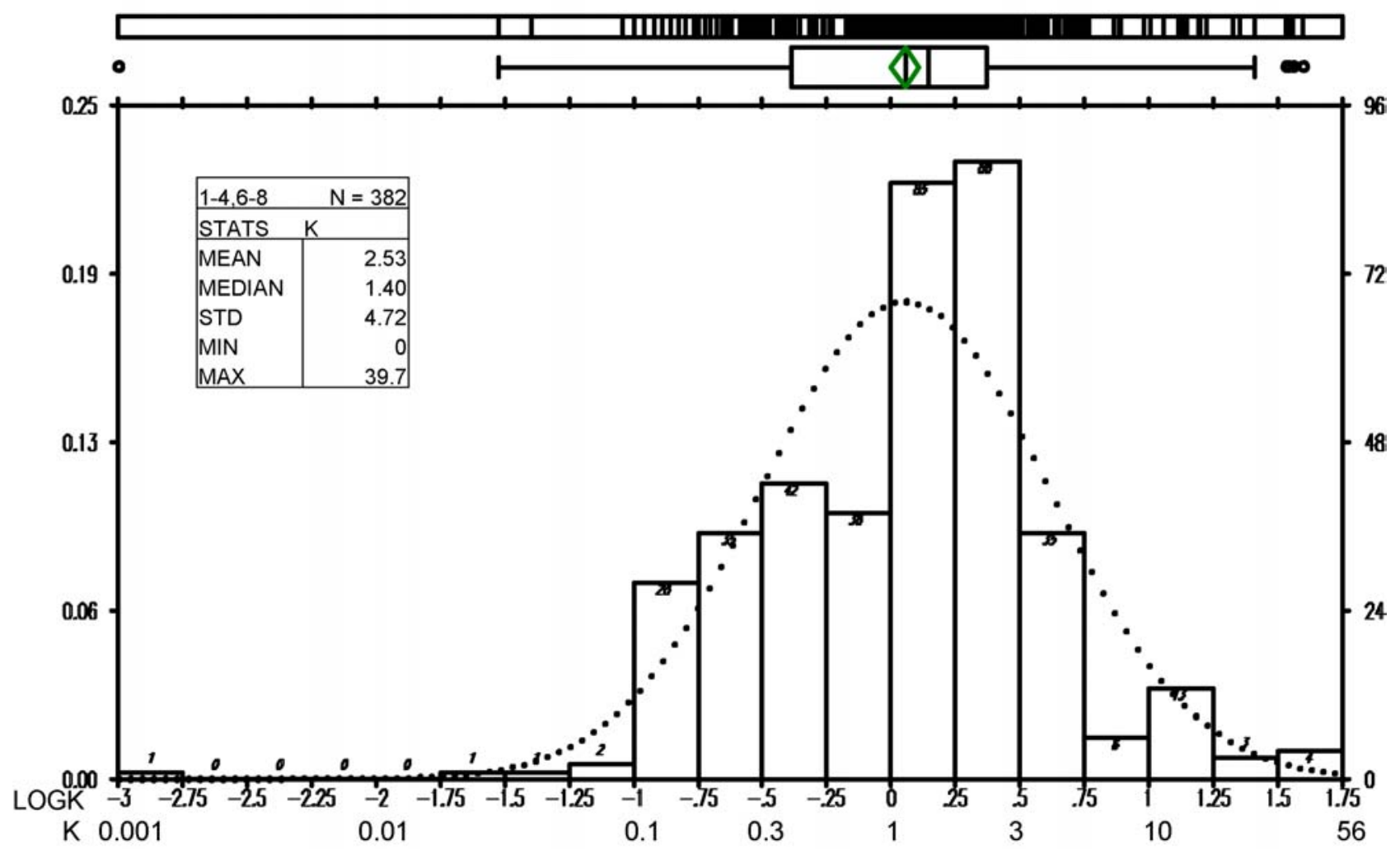

Figure 5. Data distribution display for measured susceptibility values at sites 1-4 and 6-8.

Site 5 has mean and median susceptibility values that are significantly higher than the combined data from sites 1-4 and 6-8 (see Appendix, site 5 mean $=8.82 \times 10^{-3}$ SI, median $=4.69 \mathrm{x}$ $\left.10^{-3} \mathrm{SI}\right)$. At this field location significant orange staining was observed and orange-stained sand yielded measured susceptibilities to $15 \times 10^{-3} \mathrm{SI}$. Several serpentinite boulders (susceptibilities to greater than $50 \times 10^{-3} \mathrm{SI}$ ) were also present at this location. It appears that some form of geochemical alteration may be concentrating magnetic minerals at this site.

Site 9 has mean and median susceptibility values that are significantly lower than the combined data from sites 1-4 and 6-8 (see Appendix, site 9 mean $=0.75 \times 10^{-3}$ SI, median $=0.20 \mathrm{x}$ $10^{-3} \mathrm{SI}$ ). This field site is geologically distinct from the other sites. The susceptibilities are 
measured on river cobbles rather than sandy cliffs or riverbank. The river cobbles are predominantly non-magnetic greywacke eroded from the Chugach accretionary complex to the east of the study area. Five high value outliers (see figure 4) of the 46 measurements appeared to be plutonic rocks. The low measured susceptibility of Chugach accretionary rocks indicates that the magnetic Quaternary section is not primarily derived from those rocks.

\section{Discussion}

Numerous short-wavelength, linear magnetic anomalies are observed in the detailed aeromagnetic surveys over the upper Cook Inlet (Saltus and others, 2001). In particular, some short-wavelength aeromagnetic low/high pairs correlate with topographic features such as beach cliffs (figure 6). In the Salamatof Beach area, these anomalies have total amplitudes (trough to peak) of 4 to $21 \mathrm{nT}$ and wavelengths of about $500 \mathrm{~m}$ (figures 6 and 7, table 3). Using an approximate formula for calculating the magnetic effect of a thin sheet (Nettleton, 1976), we can say that the total magnetic anomaly (V) is related to the magnetic intensity of the cliff (I), the height of the cliff ( $t$ ), and the height of measurement (flight height above the center of the cliff, $z$ ) by

$$
\mathrm{V}=2 \mathrm{It} / \mathrm{z}
$$

The magnetic intensity of the cliff is a product of the amplitude of the Earth's magnetic field (about 55,250 nT in this part of Alaska) and the magnetic susceptibility of the cliff. Using these relations, we can estimate the apparent susceptibility of the cliff from the anomalies observed on aeromagnetic profiles crossing the cliff (table 3). Only the labeled anomalies were used for these calculations. The high amplitude features on the intervening profiles are probably caused by 
man-made objects, such as the dock and industrial facilities, that are located between profiles e and f (figure 6).

The calculated apparent susceptibilities range from $1.46 \times 10^{-3}$ to $9.9 \times 10^{-3}$ SI for these cliff-crossing profiles, with a mean value of $4.77 \times 10^{-3} \mathrm{SI}$. This mean value is about twice the mean value for the Quaternary section as measured in situ (2.53 x $10^{-3} \mathrm{SI}$, figure 5), but is well within the standard deviation of $\pm 4.72 \times 10^{-3} \mathrm{SI}$ for this overall Quaternary section mean (figure 5). From this comparison, it appears that, in general, measured susceptibilities are systematically lower than values required to explain the cliff anomalies by up to 50 percent. 


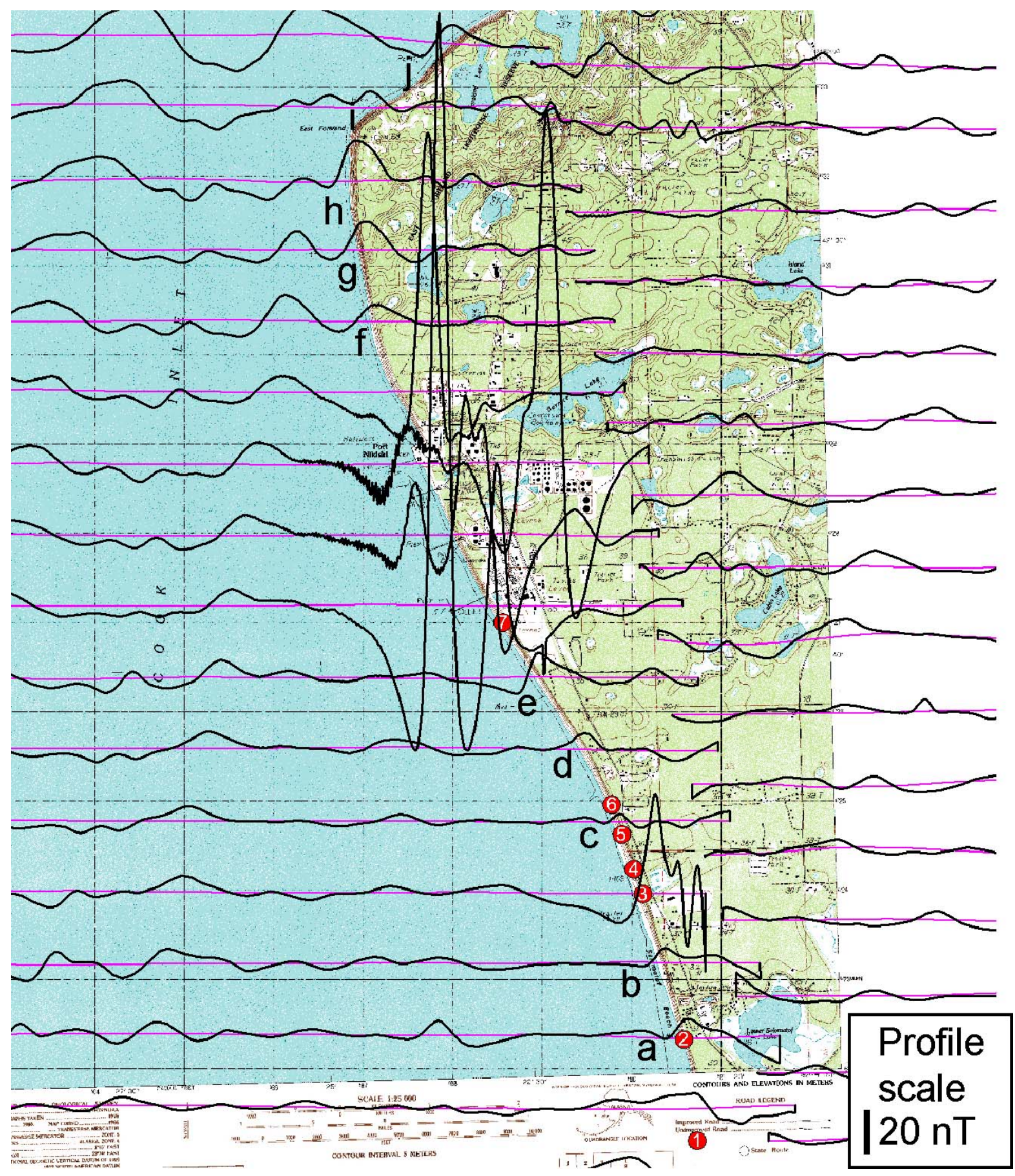

Figure 6. Aeromagnetic data profiles crossing the beach cliffs near Nikishka, Alaska.

Magenta lines: aeromagnetic flight path; black lines: filtered aeromagnetic amplitude profiles. Numbered circles are susceptibility measurement sites. 

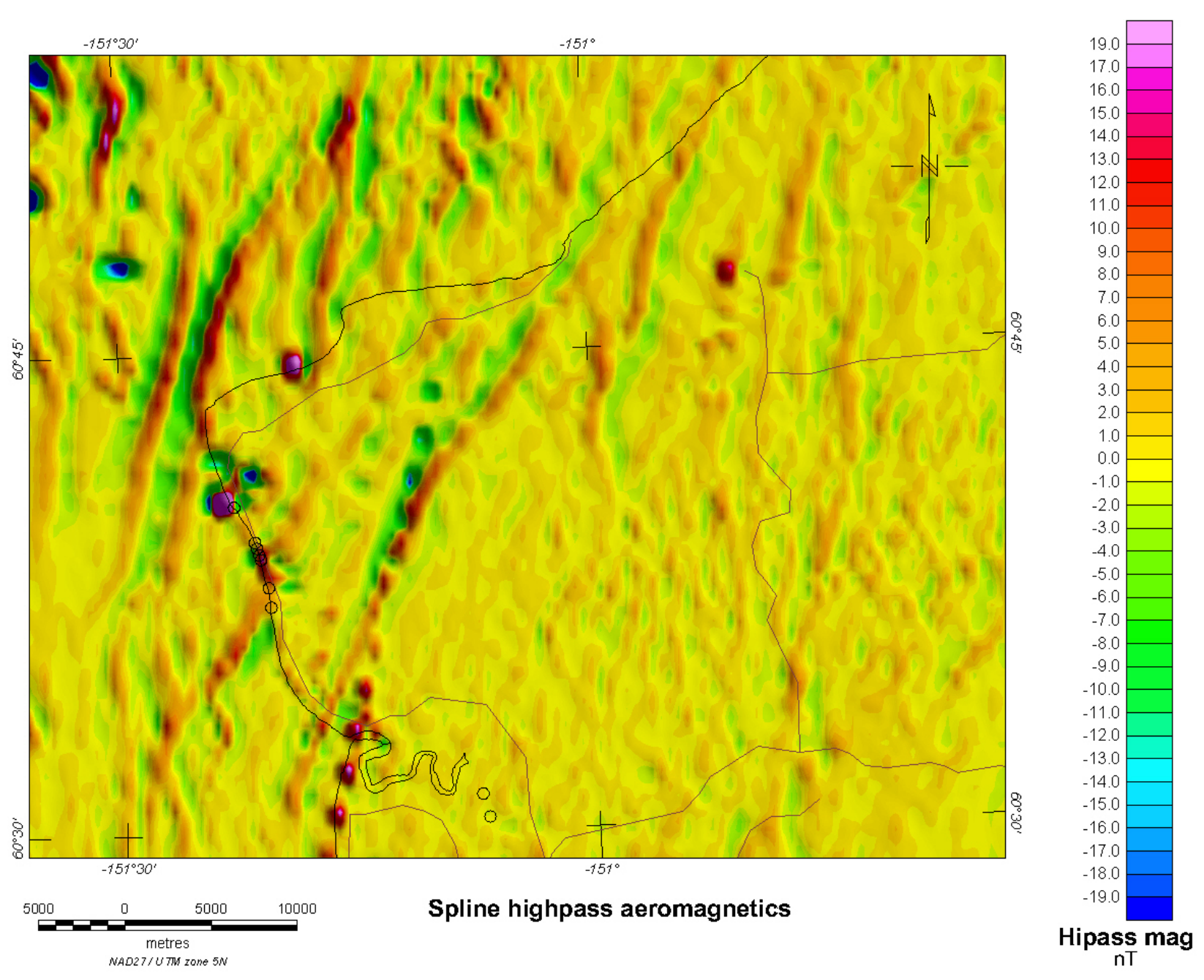

Figure 7. Residual aeromagnetic anomalies surrounding the Nikishka, Alaska, region.

Black lines outline coasts. Brown lines are roadways. Circles show susceptibility measurement sites.

Aeromagnetic profile "a" (figure 6) crosses the beach cliff at susceptibility measurement site 2. A detailed, two-dimensional model (figure 8) compares two calculated anomalies with the observed magnetic profile. A model susceptibility of $3.7 \times 10^{-3}$ SI provides the best match to the anomaly amplitude. If we use the mean measured susceptibility for this site $\left(3.0 \times 10^{-3} \mathrm{SI}\right)$, then we only predict about 80 percent of the full anomaly. For this detailed comparison we find, therefore, that measured susceptibilities are about 20 percent too low to explain the observed anomaly. The 
detailed model susceptibility of $3.7 \times 10^{-3}$ SI agrees well with the idealized model susceptibility calculation for this profile (table 3).

Table 3. Apparent susceptibilities from aeromagnetic profiles that cross over beach cliffs in the Salamatof to East Foreland region, Kenai Peninsula, Alaska.

Observed anomaly vs cliff height, Salamatof to East Foreland, Kenai Peninsula, Alaska

$\begin{array}{lllll}\text { Profile } & \text { Anomaly (nT) } & \text { Cliff (m) } & \left.\text { Flight Height (ft) Calc K (SIx10 }{ }^{-3}\right) \\ \text { L41590 (a) } & 8.9 & 30 & 413 & 3.74 \\ \text { L41580 (b) } & 8.2 & 30 & 503 & 4.30 \\ \text { L41560 (c) } & 4.04 & 35 & 422 & 1.46 \\ \text { L41550 (d) } & 8.03 & 30 & 478 & 3.98 \\ \text { L41540 (e) } & 18.67 & 30 & 508 & 9.90 \\ \text { L41490 (f) } & 12.73 & 25 & 536 & 8.74 \\ \text { L41480 (g) } & 17.42 & 45 & 473 & 5.36 \\ \text { L41470 (h) } & 20.81 & 60 & 440 & 4.11 \\ \text { L41460 (I) } & 5.7 & 50 & 488 & 1.60 \\ \text { L41450 (j) } & 15.52 & 55 & 553 & 4.53\end{array}$




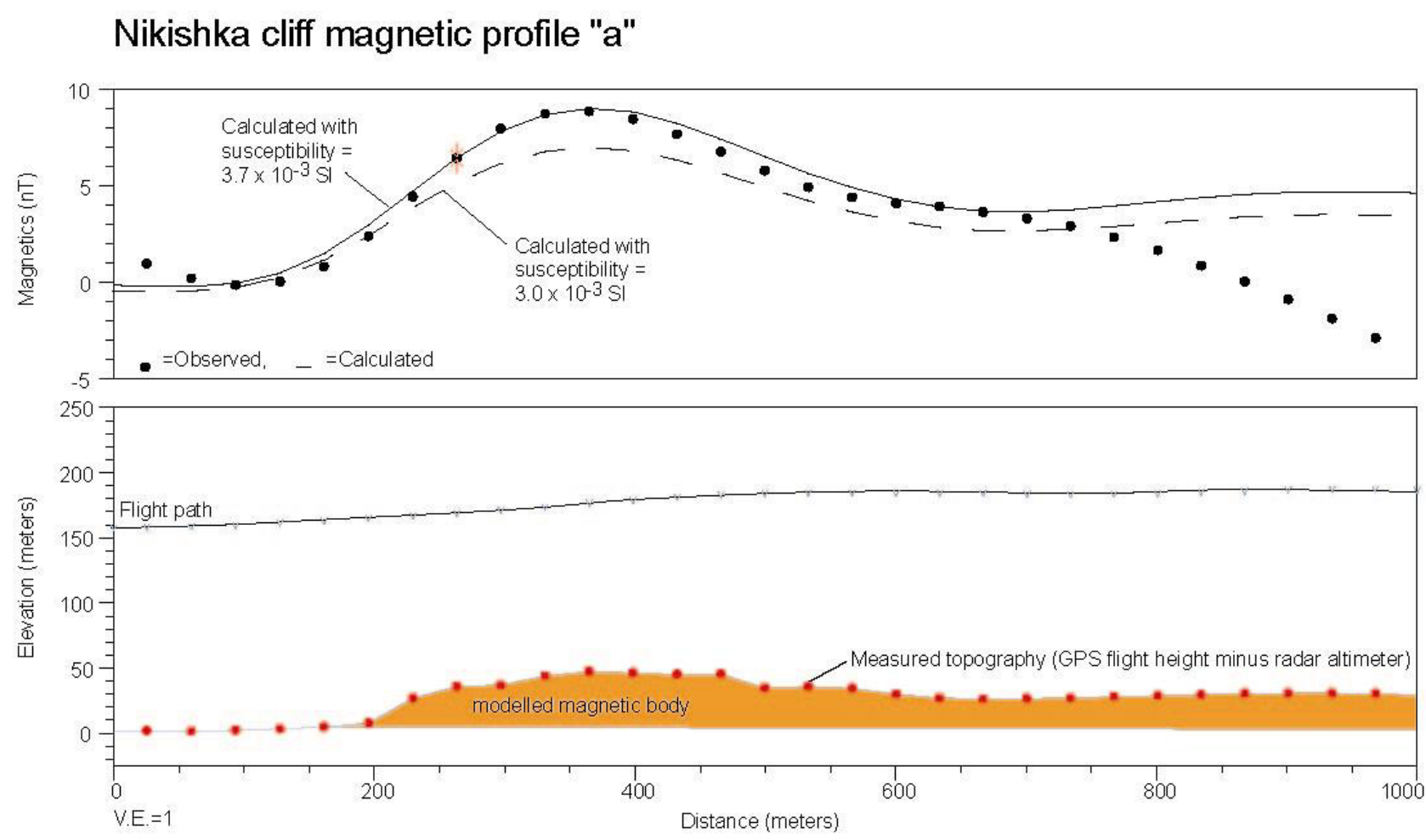

Figure 8. Detailed, two-dimensional anomaly calculation model along cliff profile "a".

Taken together, the field and profile evidence is consistent with bulk susceptibilities of the Quaternary section, at least locally, reaching and possibly exceeding $5 \times 10^{-3}$ SI. Particularly for shallow-sourced (generally short-wavelength) aeromagnetic anomalies, materials with these susceptibilities could represent a significant source of observed anomalies of amplitudes up to about $20 \mathrm{nT}$ on low-level aeromagnetic profiles collected in the upper Cook Inlet. According to Glass (1996), the proglacial lake and fluvial deposits in this region reach a maximum thickness of about $230 \mathrm{~m}$ along the coast north of East Foreland. If we use this value as the maximum thickness of an edge feature (a channel cut, for example), deposits with this susceptibility could produce short wavelength (less than $1 \mathrm{~km}$ ) aeromagnetic anomalies of up to about $40 \mathrm{nT}$ (assuming a bulk susceptibility of $5 \times 10^{-3} \mathrm{SI}$ for the material juxtaposed against non-magnetic material). 


\section{Conclusions}

Magnetic susceptibilities were measured on Quaternary deposits exposed at nine sites near Nikishka and Soldotna on the Kenai Peninsula, Alaska. The overall mean measured susceptibility for these Quaternary deposits was $2.53 \times 10^{-3}$ SI. At one measurement site, the mean susceptibility was $8.82 \times 10^{-3}$ SI. However, this mean included some very high measurements from serpentinite boulders and orange staining suggests that geochemical alteration affects the site; the median susceptibility at the same site was $4.69 \times 10^{-3}$ SI. Analysis of low-level aeromagnetic profiles that traverse the beach cliffs between Salamatof and East Foreland yields calculated model susceptibilities that range from 1.46 to $9.9 \times 10^{-3}$ SI with a mean of $4.77 \times 10^{-3}$ SI. The measurements and analyses in this report show that, at least locally, Quaternary deposits in the upper Cook Inlet are sufficiently magnetic to produce low-level, short-wavelength (generally shorter than $1 \mathrm{~km}$ ) aeromagnetic anomalies with amplitudes up to $10 \mathrm{~s}$ of $\mathrm{nT}$. Comparison of measured and modeled susceptibility values for the beach cliffs suggest that measured susceptibilities may underestimate the true bulk susceptibility values by 20 percent to 50 percent.

\section{References}

Altstatt, A.A., Saltus, R.W., Bruhn, R.L., and Haeussler, P.J., 2002, Magnetic susceptibilities measured on rocks of the upper Cook Inlet, Alaska: USGS Open-File Report 02-0139 [http://pubs.usgs.gov/of/2002/ofr-02-0139/].

Glass, R.L., 1996, Ground-water conditions and quality in the western part of Kenai Peninsula, southcentral Alaska: USGS Open-file report 96-466, 66 pp.

Saltus, R.W., Haeussler, P.J., Bracken, R.E., Doucette, J.P., and Jachens, R.C., 2001, Anchorage Urban Region Aeromagnetics (AURA) Project - Preliminary Geophysical Results: USGS OpenFile Report 01-0085 [http://pubs.usgs.gov/of/2001/ofr-01-0085//] 


\section{Appendix: Site data}

\section{Site: 03RS001}

Date: 9 August 2003

Field Programme: Kenai 2003

Latitude: $60^{\circ} 37^{\prime} 05.8^{\prime \prime}$

Longitude: $-151^{\circ} 20^{\prime} 32.3^{\prime \prime}$

Equipment used: Kappameter K-6

Observer: Saltus

Description:

Poorly consolidated beach cliff exposed along Salamatof Beach near Nikishka, Alaska. Beach access just north of LNG plant. Measurements 1-20 are in relatively competent layer $3 / 4$ way up cliff face made up of gray to orange sand with many dark grains (magnetite?). Organic layers (charcoal?) are also present. Pebble layers are also present.

Measurements 22 to 27 are from a pebbly layer at the top of the cliff that includes granite and slate-gray pebbles to 2". Finally, some measurements were made of the beach sand at the base of the cliff.

Geologic Unit:

Quaternary fluvial and glacial deposits

Measured Susceptibility:

LINK TO DATA TABLE

Statistics:

\begin{tabular}{|l|lll|}
\hline \multicolumn{2}{|l|l}{ 03RS001 } & $\mathrm{N}=$ & 34 \\
\hline STATS & $\mathrm{K}$ & LOGK & $10^{\wedge}$ LOGK \\
\hline MEAN & 1.72 & 0.15 & 1.43 \\
MEDIAN & 1.77 & 0.25 & 1.76 \\
STD & 0.92 & 0.30 & 1.99 \\
MIN & 0.23 & & \\
MAX & 4.04 & & \\
\hline
\end{tabular}

Photos:

P8090055 P8090056 P8090057 P8090058 P8090059 P8090060 


\section{Site: 03RS002}

Date: 9 August 2003

Field Programme: Kenai 2003

Latitude: $60^{\circ} 37^{\prime} 42.6^{\prime \prime}$

Longitude: $-151^{\circ} 20^{\prime} 40.1^{\prime \prime}$

Equipment used: Kappameter K-6

Observer: Saltus

Description:

Poorly consolidated beach cliff exposed along Salamatof Beach near Nikishka, Alaska. Beach access just north of LNG plant. Good exposure of cobbly and fine-grained portion of section. Site is just south of "Crotch Creek" (labeled as such in Haeussler unpublished field notes). Lower part of exposed section has cobbles (34 measurements - clast sample 03RS002A). Section becomes more fine-grained moving up the cliff (sand/clay - dirt sample 03RS002B). The upper cliff is very fine grained with small pebbles and distinct stratification. Measurements were taken on rocks exposed on the beach (float) below the cliff site. Lots of big float observed on the beach including bathtub size to fist sized rocks including some coarse grained and granitic (sample 03RS002C).

Geologic Unit:

Quaternary fluvial and glacial deposits

Measured Susceptibility:

LINK TO DATA TABLE

Statistics:

\begin{tabular}{|l|lll|}
\hline 03RS002 & $\mathrm{N}=$ & 141 \\
\hline STATS & $\mathrm{K}$ & LOGK & $10^{\wedge}$ LOGK \\
\hline MEAN & 2.98 & 0.04 & 1.10 \\
MEDIAN & 1.40 & 0.15 & 1.40 \\
STD & 6.10 & 0.61 & 4.06 \\
MIN & 0.04 & & \\
MAX & 39.7 & & \\
\hline
\end{tabular}

Photos:

P8090061 P8090062 P8090063 P8090064 P8090065 P8090066 P8090067 P8090068 P8090069 P8090070 P8090071 P8090072 P8090073 P8090074 


\section{Site: 03RS003}

Date: 9 August 2003

Field Programme: Kenai 2003

Latitude: $60^{\circ} 38^{\prime} 35.6^{\prime \prime}$

Longitude: $-151^{\circ} 21^{\prime} 07.6^{\prime \prime}$

Equipment used: Kappameter K-6

Observer: Saltus

\section{Description:}

Poorly consolidated beach cliff exposed along Salamatof Beach near Nikishka, Alaska. Beach access just north of LNG plant. At "Crotch Creek" - see field notes of Peter Haeussler (1996) for cross-section description. Lower part of the section has rounded cobbles with orange staining (highest susceptibilities in black matrix, not on cobbles). Upper part of section is very fine, chalky, gray/white material (which has essentially zero susceptibility).

Geologic Unit:

Quaternary fluvial and glacial deposits

Measured Susceptibility:

LINK TO DATA TABLE

Statistics:

\begin{tabular}{|l|lll|}
\hline 03RS003 & $\mathrm{N}=$ & 21 \\
\hline STATS & $\mathrm{K}$ & LOGK & $10^{\wedge}$ LOGK \\
\hline MEAN & 1.92 & -0.08 & 0.83 \\
MEDIAN & 1.40 & 0.15 & 1.40 \\
STD & 1.63 & 0.89 & 7.82 \\
MIN & 0.001 & & \\
MAX & 5.15 & & \\
\hline
\end{tabular}

Photos:

P8090075 P8090076 P8090077 P8090078 P8090079 P8090080 P8090081 


\section{Site: 03RS004}

Date: 9 August 2003

Field Programme: Kenai 2003

Latitude: $60^{\circ} 38^{\prime} 44.7^{\prime \prime}$

Longitude: $-151^{\circ} 21^{\prime} 13.9^{\prime \prime}$

Equipment used: Kappameter K-6

Observer: Saltus

Description:

Poorly consolidated beach cliff exposed along Salamatof Beach near Nikishka, Alaska. Beach access just north of LNG plant. This site is near hanging foundation slab at top of cliff from house undercut by erosion. Part of exposure is chalky white layer beneath a cobbly zone.

Geologic Unit:

Quaternary fluvial and glacial deposits

Measured Susceptibility:

LINK TO DATA TABLE

Statistics:

\begin{tabular}{|l|lll|}
\hline 03RS004 & $\mathrm{N}=$ & 10 \\
\hline STATS & $\mathrm{K}$ & LOGK & $10^{\wedge}$ LOGK \\
\hline MEAN & 2.05 & 0.31 & 2.03 \\
MEDIAN & 2.03 & 0.31 & 2.03 \\
STD & 0.28 & 0.06 & 1.14 \\
MIN & 1.61 & & \\
MAX & 2.67 & & \\
\hline
\end{tabular}

Photos:

P8090082 P8090083 P8090084 P8090085 P8090086 P8090087 


\section{Site: 03RS005}

Date: 9 August 2003

Field Programme: Kenai 2003

Latitude: $60^{\circ} 38^{\prime} 57.3^{\prime \prime}$

Longitude: $-151^{\circ} 21^{\prime} 22.1^{\prime \prime}$

Equipment used: Kappameter K-6

Observer: Saltus

\section{Description:}

Poorly consolidated beach cliff exposed along Salamatof Beach near Nikishka, Alaska. Beach access just north of LNG plant. Dark sand layer and orange-stained sand leaching from bottom of the cliff. Sample taken of magnetic sand with in situ susceptibilities up to $15 \times 10^{-3} \mathrm{SI}$ (very magnetic for sand). Serpentinite boulder with susceptibility over 50 $\mathrm{x} 10^{-3} \mathrm{SI}$ measured in the area as well. Susceptibilities at this site statistically higher and distinct from other Q sites measured.

Geologic Unit:

Quaternary fluvial and glacial deposits

Measured Susceptibility:

LINK TO DATA TABLE

Statistics:

\begin{tabular}{|l|lll|}
\hline 03RS005 & $\mathrm{N}=$ & 23 \\
\hline STATS & $\mathrm{K}$ & LOGK & $10^{\wedge}$ LOGK \\
\hline MEAN & 8.82 & 0.74 & 5.43 \\
MEDIAN & 4.69 & 0.67 & 4.69 \\
STD & 14.41 & 0.33 & 2.14 \\
MIN & 3.08 & & \\
MAX & 57.6 & & \\
\hline
\end{tabular}

Photos:

P8090088 P8090089 


\section{Site: 03RS006}

Date: 9 August 2003

Field Programme: Kenai 2003

Latitude: $60^{\circ} 39^{\prime} 08.2^{\prime \prime}$

Longitude: $-151^{\circ} 21^{\prime} 28.9^{\prime \prime}$

Equipment used: Kappameter K-6

Observer: Saltus

Description:

Poorly consolidated beach cliff exposed along Salamatof Beach near Nikishka, Alaska. Beach access just north of LNG plant. Orange-stained seep and eroded amphitheater. Mixture of cobbly, sandy, and ashy layers.

Geologic Unit:

Quaternary fluvial and glacial deposits

Measured Susceptibility:

LINK TO DATA TABLE

Statistics:

\begin{tabular}{|l|lll|}
\hline O3RS006 & $\mathrm{N}=$ & 27 \\
\hline STATS & $\mathrm{K}$ & LOGK & $10^{\wedge}$ LOGK \\
\hline MEAN & 1.43 & 0.00 & 1.00 \\
MEDIAN & 1.39 & 0.14 & 1.39 \\
STD & 1.12 & 0.39 & 2.46 \\
MIN & 0.24 & & \\
MAX & 3.67 & & \\
\hline
\end{tabular}

Photos:

P8090090 P8090091 P8090092 P8090093 


\section{Site: 03RS007}

Date: 9 August 2003

Field Programme: Kenai 2003

Latitude: $60^{\circ} 40^{\prime} 15.1$ '

Longitude: $-151^{\circ} 22^{\prime} 45.8^{\prime \prime}$

Equipment used: Kappameter K-6

Observer: Saltus

Description:

Poorly consolidated beach cliff exposed along Salamatof Beach near Nikishka, Alaska. Beach access just north of LNG plant. Cliff here is very different from cliff further south. Section is dirt rather than sand/silt/clay. Is this a lake deposit? However, it still is as magnetic as the other sites. Also took measurements on beach gravels at site - they are less magnetic than the dirt and sand layers.

Geologic Unit:

Quaternary fluvial and glacial deposits

Measured Susceptibility:

LINK TO DATA TABLE

Statistics:

\begin{tabular}{|l|lll|}
\hline 03RS007 & $\mathrm{N}=$ & 31 \\
\hline STATS & $\mathrm{K}$ & LOGK & $10^{\wedge}$ LOGK \\
\hline MEAN & 1.63 & 0.14 & 1.37 \\
MEDIAN & 1.59 & 0.20 & 1.59 \\
STD & 0.81 & 0.29 & 1.96 \\
MIN & 0.16 & & \\
MAX & 3.27 & & \\
\hline
\end{tabular}

Photos:

P8090094 P8090095 


\section{Site: 03RS008}

Date: 10 August 2003

Field Programme: Kenai 2003

Latitude: $60^{\circ} 30^{\prime} 53.4^{\prime \prime}$

Longitude: $-151^{\circ} 07^{\prime} 23.6^{\prime \prime}$

Equipment used: Kappameter K-6

Observer: Saltus

\section{Description:}

Poorly consolidated beach cliff exposed along Kenai River near Soldotna. Cliff here is remarkably similar to beach cliff at Salamatof Beach. Susceptibility measurements are statistically indistinguishable from most of the Nikishka sites. Measurements include cobbles at river's edge, lower cobbly layer in cliff face, orange-brown to gray sandy layers above, cross-bedded sandy layer, an upper sandy layer, and cobbles and rocks at the top of the cliff.

Geologic Unit:

Quaternary fluvial and glacial deposits

Measured Susceptibility:

LINK TO DATA TABLE

Statistics:

\begin{tabular}{|l|lll|}
\hline 03RS008 & $\mathrm{N}=$ & 118 \\
\hline STATS & $\mathrm{K}$ & LOGK & $10^{\wedge}$ LOGK \\
\hline MEAN & 2.86 & 0.03 & 1.08 \\
MEDIAN & 1.13 & 0.05 & 1.13 \\
STD & 5.20 & 0.59 & 3.90 \\
MIN & 0.1 & & \\
MAX & 35 & & \\
\hline
\end{tabular}

Photos:

P8100134 P8100135 P8100136 P8100137 P8100138 P8100139 P8100140 


\section{Site: 03RS009}

Date: 10 August 2003

Field Programme: Kenai 2003

Latitude: $60^{\circ} 30^{\prime} 23.0^{\prime \prime}$

Longitude: $-151^{\circ} 06^{\prime} 59.5^{\prime \prime}$

Equipment used: Kappameter K-6

Observer: Saltus

\section{Description:}

Gravel bar along Kenai River near Soldotna. Mostly greywacke stones and cobbles with occasional coarse-grained igneous rock.

Geologic Unit:

Quaternary fluvial and glacial deposits

Measured Susceptibility:

LINK TO DATA TABLE

Statistics:

\begin{tabular}{|l|lll|}
\hline 03RS009 & $\mathrm{N}=$ & 46 \\
\hline STATS & $\mathrm{K}$ & LOGK & $10^{\wedge}$ LOGK \\
\hline MEAN & 0.75 & -0.64 & 0.23 \\
MEDIAN & 0.20 & -0.70 & 0.20 \\
STD & 2.07 & 0.51 & 3.22 \\
MIN & 0.03 & & \\
MAX & 11.4 & & \\
\hline
\end{tabular}

Photos:

No photos available for this site 